\title{
Unicorn Poo and Blessed Waters: COVID-19 Quackery and FDA Warning Letters
}

\author{
Katrina A. Bramstedt, $\mathrm{PhD}, \mathrm{MA}^{1,2}$ D
}

Received: 5 August 2020 / Accepted: 19 September 2020 / Published online: 1 October 2020

(c) The Drug Information Association, Inc 2020

\begin{abstract}
Background The COVID-19 pandemic has created a global setting of clinical crisis and human anxiety. Without available safe and effective vaccines and cures, an unscrupulous marketplace has emerged selling COVID-19 quackery (fraudulent misrepresentation of preventions and treatments).

Methods US Food and Drug Administration (FDA) Warning Letters issued from March 2020 to July 2020 were analyzed for themes pertaining to unapproved, adulterated, and misbranded COVID-19 products.

Results During this period, the FDA issued 3,139 Warning Letters of which 98 (3.14\%) of these were focused on COVID19-related drugs, devices, biologics, and dietary supplements (products and ingredients). Specifically, these Warning Letters revealed regulatory nonconformities involving 40 identified herbs, 22 minerals/compounds, 6 devices and biologicals, and 3 vitamins. Products included hand sanitizers; COVID-19 antibody test kits; herbal teas and tinctures; nasal gel; toothpaste; and 1 vaccine. Nine Warning Letters were issued for products being sold via the Amazon online shopping platform.

Conclusion A small percentage of FDA Warning Letters recently have been focused on COVID-19. These Letters expose the blatant and potentially harmful quackery of vendors across the world who prioritize financial gain over clinical beneficence. Patient history-taking should include queries about non-traditional and unapproved products to identify, document, and report potentially harmful quackery. FDA Warning Letters are a component of meaningful corrective action; however, greater effort in spreading awareness of such misrepresented, unapproved, and adulterated products is needed to deter purchases of such products.
\end{abstract}

Keywords COVID-19 $\cdot$ Severe acute respiratory syndrome coronavirus $2 \cdot$ Quackery $\cdot$ Bioethics $\cdot$ Standards

\section{Introduction}

On 30 January 2020, the World Health Organization Director-General declared a Public Health Emergency of International Concern regarding COVID-19 [1]. As of 31 July 2020, there have been over 17 million cases of COVID-19 globally, with nearly 674,000 deaths [2]. All vaccines are currently investigational. The investigational antiviral drug, remdesivir, has been conditionally approved by Australia, Singapore, Japan, USA, and the European Union for severely

Katrina A. Bramstedt

txbioethics@yahoo.com

1 Luxembourg Agency for Research Integrity (LARI), 6, Avenue des Hauts-Fourneaux, 4362 Esch-sur-Alzette, Luxembourg

2 Medical Program, Bond University Faculty of Health Sciences and Medicine, Gold Coast, QLD, Australia ill and hospitalized patients [3, 4]. Currently, no other drugs have received approval for the prevention or treatment of COVID-19 (also known as severe acute respiratory syndrome coronavirus 2 (SARS-CoV-2)), and additional new and existing vaccines and drugs are being tested via clinical trials worldwide. With morbidity and mortality soaring, and available treatment limited, patients and families are vulnerable to lures for remedies.

The US Food and Drug Administration (https://www.fda. gov) is the US regulatory agency for human and veterinary drugs (prescription and non-prescription), medical devices, biologicals (including vaccines), and dietary supplements ${ }^{1}$

\footnotetext{
1 The FDA regulates dietary supplements via the Dietary Supplement Health and Education Act of 1994 (DSHEA). Manufacturers and distributors of dietary supplements are responsible for the safety and labeling of their products before marketing to ensure that they satisfy all DSHEA and FDA requirements. Medical claims (e.g., "This herb reduces the frequency of COVID-19 cough") are not permitted in USA for herbal supplements.
} 
(among other regulated items). Various regulations are in place in the US regarding the safety, efficacy, security, and marketing of regulated products and when the FDA determines significant violations, they issue Warning Letters (WL) [5]. For example, a WL can be issued to a manufacturer who promotes a product with fraudulent claims about the product's ability to mitigate, prevent, treat, diagnose, or cure COVID-19. A WL is a public record document that identifies the name and address of the violator (e.g., manufacturer), the violation, and corrective action requirements and timeframes.

\section{Methods}

On 31 July 2020, the open access, online database of US FDA WLs [5] was searched using the search term "COVID$19 "{ }^{2}$ No other search filters were used. Results were exported using the database's "Export Excel" feature and sorted by letter issue date. Each letter was manually read by the author and the following noted: WL month of issue, nonconformance category (misbranded, adulterated, unapproved); product type as recorded by FDA (drug, device, biological, food \& beverage, dietary supplement); product scope (prevention, treatment, antibody test); problematic ingredient. The problematic ingredients were then classified according to the following: herbals (including undefined herbals, ${ }^{3}$ nosodes, homeopathies, and ayurvedics) and non-herbals (i.e., minerals/compounds/drugs/biologics/vitamins/misc.)

\section{Results}

The WL database contained 3,139 WLs and 98 (3.14\%) of these WLs included regulatory violations pertaining to COVID-19 (Table 1). Most WLs were issued in April $(n=29)$ and May $2020(n=30)$. Most were issued to recipients in USA $(n=82)$, with a few being sent to Canada, the UK, and Asia. Most of the WLs $(n=88 ; 89.8 \%)$ identified nonconformities with products classified as drugs. More specifically, the WLs revealed regulatory nonconformities involving 40 identified herbs (Table 2), 22 minerals/compounds, 6 devices and biologicals, and 3 vitamins (Table 3). In addition to unusual products such as "UNICORN POO" [6] and "blessed waters" [7], WLs identified the following ingredients most frequently: vitamin C ( $n=14 \mathrm{WLs})$, cannabidiol/CBD ( $n=13 \mathrm{WLs})$, vitamin D/D3 ( $n=12 \mathrm{WLs})$, silver/colloidal silver $(n=11$ WLs), elderberry ( $n=6 \mathrm{WLs})$, ritonavir ( $n=6 \mathrm{WLs})$, and

\footnotetext{
2 The search term "COVID-19" was chosen as this term was already visible as the FDA subject term used in the WL database for this disease topic. In the database, "COVID-19" was already pre-linked to the term "coronavirus" so there was no need to search both terms.

3 "herbal medicine", "natural herbs", "teas", "botanical oils", "essential oils", "tincture."
}

Table 1 US Food and Drug Administration Warning Letter $(N=98)$ Findings Summary.

\begin{tabular}{|c|c|}
\hline & $n(\%)$ \\
\hline \multicolumn{2}{|c|}{ Warning letter month of issue } \\
\hline March 2020 & $14(14.3)$ \\
\hline April 2020 & $29(29.6)$ \\
\hline May 2020 & $30(30.1)$ \\
\hline June 2020 & $15(15.3)$ \\
\hline July 2020 & $11(11.2)$ \\
\hline \multicolumn{2}{|l|}{ Recipient location } \\
\hline USA & $82(83.7)$ \\
\hline Canada & $4(4.1)$ \\
\hline India & $4(4.1)$ \\
\hline Hong Kong & $2(2.0)$ \\
\hline UK & $2(2.0)$ \\
\hline \multicolumn{2}{|l|}{ Product(s) type* } \\
\hline Drug & $88(89.8)$ \\
\hline Food \& beverages & $5(5.1)$ \\
\hline Device & $3(3.1)$ \\
\hline Biologics & $3(3.1)$ \\
\hline Dietary supplement & $3(3.1)$ \\
\hline \multicolumn{2}{|l|}{ Scope } \\
\hline Prevention \& treatment & $49(50.0)$ \\
\hline Prevention & $27(27.6)$ \\
\hline Treatment & $19(19.4)$ \\
\hline COVID-19 antibody test & $3(3.1)$ \\
\hline \multicolumn{2}{|l|}{$\operatorname{Nonconformity}(s)^{*}$} \\
\hline Unapproved $^{\dagger}$ & $94(95.9)$ \\
\hline Misbranded ${ }^{\ddagger}$ & $94(95.9)$ \\
\hline Adulterated ${ }^{\S}$ & $4(4.1)$ \\
\hline
\end{tabular}

*Some Warning Letters cite more than one product type, product, and nonconformity

Unapproved new drugs sold in violation of section 505(a) of the Federal Food, Drug, and Cosmetic Act (FD\&C Act), 21 United States Code (U.S.C.) § 355(a)

${ }^{\ddagger}$ Misbranded drugs under section 502 of the FD\&C Act, 21 U.S.C. $\S$ 352

${ }^{\S}$ Adulterated under section 501(f)(1)(B) of the FD\&C Act, 21 U.S.C. $\S 351(\mathrm{f})(1)(\mathrm{B})$, because the firm does not have approved applications for premarket approval in effect pursuant to section 515(a) of the FD\&C Act, 21 U.S.C. $\$ 360$ e(a), or approved applications for an investigational device exemption under section 520(g) of the FD\&C Act, 21 U.S.C. $\$ 360 \mathrm{j}(\mathrm{g})$

zinc ( $n=6 \mathrm{WLs})$. WLs were issued regarding 4 hand sanitizers, 3 COVID-19 antibody test kits, and 1 vaccine, as well as other products such as herbal teas and tinctures, nasal gel, and toothpaste. Nine WLs were issued for products being sold via the Amazon online shopping platform. ${ }^{4}$ Twenty-seven

\footnotetext{
${ }^{4}$ WLs were issued directly to the "Amazon Associate" [e.g., affiliate seller/referrer/manufacturer] not Amazon.com, Inc. None of these WL products are manufactured by Amazon.com, Inc.
} 
Table 2 Herbal Ingredients Identified in COVID-19-Related WLs $(N=98)$.

Herbals \# \#Ls*

Undefined herbal (e.g., "herbal medicine", "natural herbs", "teas", "botanical oils", "essential oils", "tincture")

Elderberry

Lianhua Qingwen/Qinwen

Astragalus

Echinacea

Licorice root

Agaricus

Andrographis

Artemisia annua

Ashwaghanda

Berberine

Blessed waters

Boneset (Eupatorium perfoliatum)

Bupleurum

Calendula

Cinnamon

Cod liver oil

Cyprus

Eucalyptus

Garlic

Golden flower

Grapefruit seed

Henna

Huang Qin

Japanese honeysuckle

Jin Yin Hua

Kratom (Mitragyna speciose)

Lian Qiao

Lianhua Qingwen jiaonang

Lomatium

Medicinal mushrooms

Nobel laurel

Oregano

Peppermint

Qing Fei Pai Du Tang

Quercetin

Rosemary

Shuang Huang Lian

Unicorn poo ("fruity honey")

Witch hazel

Withania somnifera

Nosodes, Homeopathies, Ayurvedic Products (all not specifically defined in WL)

Undefined (not defined in WL)

*Some WLs cite more than one product and some products have multiple ingredients
9

6

3

2

2

1

1

1

1

1

1

1

1

1

1

1

1

1

1

1

1

1

1

1

1

1

1

1

1

1

1

1

5

4 
Table 3 Non-herbal Ingredients Identified in COVID-19-Related WLs $(\mathrm{N}=98)$.

\begin{tabular}{|c|c|}
\hline & \# WLs* \\
\hline \multicolumn{2}{|l|}{ Minerals/compounds/misc } \\
\hline Cannabidiol/CBD & 13 \\
\hline Silver/colloidal silver & 11 \\
\hline Zinc & 6 \\
\hline Chlorine dioxide/ "chlorine-based" & 2 \\
\hline Colostrum & 2 \\
\hline Copper & 2 \\
\hline Hypochlorous acid & 1 \\
\hline Iodine & 2 \\
\hline Magnesium & 2 \\
\hline Methylene blue & 2 \\
\hline Potassium & 2 \\
\hline Selenium & 2 \\
\hline Arsenicum album 30 & 1 \\
\hline Carbon 60 & 1 \\
\hline Fulvic acid & 1 \\
\hline Glutathione & 1 \\
\hline Humic acid & 1 \\
\hline NAC ( $N$-acetylcysteine) & 1 \\
\hline NAD + (nicotinamide adenine dinucleotide) & 1 \\
\hline NMN (nicotinamide mononucleotide) & 1 \\
\hline Saline/sodium chloride [salt] & 1 \\
\hline Thymosin-alpha & 1 \\
\hline \multicolumn{2}{|l|}{ Drugs, devices, and biologics } \\
\hline Ritonavir (antiretroviral drug) & 6 \\
\hline Oseltamivir (antiviral drug) & 3 \\
\hline COVID-19 antibody test kit & 3 \\
\hline Arbidol® [brand name of antiviral umifenovir] & 2 \\
\hline Lopinavir (antiretroviral drug) & 2 \\
\hline Plaquenil®/hydroxychloroquine (antimalarial drug) & 2 \\
\hline Ribavirin (antiviral drug) & 2 \\
\hline "Exosome product" & 1 \\
\hline “Spike protein" (vaccine) & 1 \\
\hline Umbilical cord stem cells & 1 \\
\hline Wharton's jelly (substantia gelatinea funiculi umbilicalis) & 1 \\
\hline \multicolumn{2}{|l|}{ Vitamins } \\
\hline Vitamin C & 14 \\
\hline Vitamin D/D3 & 12 \\
\hline Vitamin E & 1 \\
\hline
\end{tabular}

*Some WLs cite more than one product and some products have multiple ingredients

(27.6\%) WLs identified products claiming to prevent COVID19 (e.g., immune system enhancement, increase interferon); 19 (19.4\%) WLs identified products claiming to treat COVID19 (e.g., cough syrup, detoxifier, antiviral, halting the cytokine cascade); and 49 (50.0\%) WLs included products with both types of claims.

\section{Discussion}

In this study, all WLs (100\%) issued by the FDA relating to COVID-19 involved quackery. This aligns with the FDA's recent project, Operation Quack Hack during which the FDA has aimed to find and stop COVID-19 fraud [8]. This is an important endeavor because online shopping makes possible global purchasing and delivery of potentially unsafe COVID-19 related products. The National Library of Medicine defines quackery as "The fraudulent misrepresentation of the diagnosis and treatment of disease" [9]. While "prevention" is not mentioned in this definition, it seems logical to include as a form of quackery when the claim involves fraudulent misrepresentation. None of the products or ingredients involved in the 98 WLs have US FDA approval for the diagnosis, treatment, or prevention of COVID-19. Notably, no WLs were issued for unapproved, misbranded, or adulterated versions of remdesivir-the only drug in the world with limited regulatory approval ${ }^{5}$ to treat COVID-19 [3, 4].

Quackery is clinically, ethically, and financially problematic. In addition to giving patients (and families) false hope and wasting resources (time and money), fraudulent products can deter patients from acquiring clinically valid interventions, causing their health status to deteriorate (with the potential for death). Also, some of these products are directly harmful. For example, 11 WLs referenced silvercontaining products, yet improper use of silver can result in toxicity such as argyria (a blue or blue-gray skin discoloration treatable only with lasers) [10]. In 1999, the FDA announced that "all over-the counter (OTC) drug products containing colloidal silver ingredients or silver salts for internal or external use are not generally recognized as safe and effective and are misbranded" [11].

Similarly, while methylene blue photoactivated with fluorescent white light has been shown to inactivate West Nile Virus in tissue culture [12], there is no evidence this translates to human clinical use in patients with COVID19. Additionally, methylene blue can interact with other medications such as serotonin reuptake inhibitors/serotonin norepinephrine reuptake inhibitors and produce neurological adverse events such as agitation, confusion, and potentially life-threatening tachycardia [13].

Quackery is common to pandemics and was evidenced during the Russian Flu, Spanish Flu, Ebola Virus, and HIV [14]. The blend of clinical unknowns, patient and family anxiety, and risk of death create a setting that is ripe for vulnerable people to be taken advantage of. In this setting, the vulnerable often look to people in positions of authority and trust for guidance and support (e.g., clinicians, therapists,

\footnotetext{
5 Approval status varies by country and is generally a preliminary or emergency use authorization rather than full regulatory approval.
} 
clergy, politicians). When these individuals are involved in pandemic quackery [15-18], the myths and false information can be difficult to debunk as they are seen to emerge from purportedly honest people with caretaking missions.

Another influential group is researchers. MEDLINE®/ PubMed $^{6}$ is viewed as a trusted source for peer-reviewed scientific content yet this database relies on the integrity of the journal peer-review process to ensure its catalogue of manuscripts are robust. While there are no foods or herbs that can prevent or cure COVID-19, PubMed currently contains full-text articles which are controversial regarding COVID-19 claims. Lee et al. have created guidelines for the prevention of COVID-19 with herbs, recommending Youngyopaedoc-san plus Bojungikgitang, and Youngyopaedoc-san plus Saengmaek-san [19]. ${ }^{7}$ Other researchers have attempted to show that COVID-19 ICU patients had a decreased trend of mortality if they had also received "Chinese herb therapy" during the course of their disease [20]. ${ }^{8}$ Research ethics committees and journal peer reviewers need to ensure robust analysis in the setting of a flurry of COVID19 submissions [21]. In the marketplace, aligning with FDA regulations, the American Herbal Products Association, the Consumer Healthcare Products Association, the Council for Responsible Nutrition, and the United Natural Products Alliance, have advised sellers of dietary supplements (e.g., vitamins, minerals, herbs) that these products must not claim to prevent, treat, or cure COVID-19 [22].

The morbidity and mortality of COVID-19 has created a need for regulatory speed and the FDA has reacted by creating the Coronavirus Treatment Acceleration Program (CTAP) [23]. To facilitate efficiency, the FDA created specific contacts for product development sponsors of COVIDrelated drugs, devices, biologics and in-vitro diagnostics. The FDA is also working with industry via the Accelerating COVID-19 Therapeutic Interventions and Vaccines (ACTIV) Partnership [24] with the aim to streamline clinical research so that effective COVID-related products can reach patients faster. Those working outside the required regulatory parameters to develop and market COVID-19 diagnostics and therapeutics are running afoul of ethics and the law.

\section{Conclusion}

Certainly, anyone offering to provide COVID-19 stem cell treatment to patients in the 'safety of their car in the parking lot' should be viewed as a quack [25]; but moreover, the outright fraud and potential harm of some of these products should alarm all stakeholders. In clinics and hospitals, patient history-taking should include queries about nontraditional and unapproved products to identify, document, and report potentially harmful quackery. Ideally, clinics and hospitals should also warn patients and families of the dangers of quackery-this could be done via print and digital posters in waiting rooms, as well as flyers mailed concurrently with healthcare invoices in the event that billing is a trigger to the uninsured or underinsured to seek alternative and unapproved interventions for COVID-19 care. As stated by the WHO [26], combatting misinformation is important and should go beyond clinical settings. Online selling and social media platforms should have policies that ethically manage pandemic misinformation and quackery. These platforms can also be a powerful voice to proactively warn people to be cautious and reflective in their purchasing, and to verify content with robust sources such as professional societies. Beyond WLs, the consequences for manufacturers and vendors should be meaningful in order to deter fraud. ${ }^{9}$ Potential examples include facility inspections, product seizure, business injunction (legal cease of business activity), professional development education (i.e., regulatory and business ethics courses), and import bans and international regulatory agency notifications for non-USA products.

\section{Author Contributions}

$\mathrm{KAB}$ is the sole author and she designed the study, collected and analyzed the data, and wrote the manuscript.

\section{Funding}

None.

\footnotetext{
${ }^{6}$ MEDLINE is a database which indexes journals which have undergone a rigorous selection process by the US National Library of Medicine. PubMed is a linked repository of full-text peer-reviewed articles. The journals associated with PubMed articles are not automatically MEDLINE-indexed. (See also Bramstedt KA. https://doi. org/10.35122/001c.13267)

7 The journal, Integrative Medicine Research, is not MEDLINEindexed but the manuscript is deposited in PubMed.

${ }^{8}$ The journal, Critical Care, is MEDLINE-indexed, with full-text manuscript deposits in PubMed.
}

\footnotetext{
9 Only 3 of 98 (3.1\%) WL recipients had received closeout letters from the FDA during the time of this study. These FDA letters all indicated that the FDA was satisfied that the violations had been corrected and informed the recipients that future FDA inspections and regulatory activities (not defined) would occur for each recipient to ensure that the violation remained suitably fixed. No other specific FDA actions were stated in the closeout letters. At the time this paper was accepted for publication no additional closeout letters had been sent by the FDA.
} 


\section{Compliance with Ethical Standards}

\section{Conflict of interest}

Prof. Bramstedt reports personal fees from AskTheEthicist LLC, outside the submitted work. The author is a former member of a US Food and Drug Administration Medical Devices Advisory Committee (2003-2011).

\section{Ethics Approval}

No human subjects. IRB/REC review not required.

\section{References}

1. World Health Organization. Statement on the second meeting of the International Health Regulations (2005) Emergency Committee regarding the outbreak of novel coronavirus $(2019-\mathrm{nCoV})$. 30 January 2020. https://www.who.int/news-room/detail/30-012020-statement-on-the-second-meeting-of-the-international-healt h-regulations-(2005)-emergency-committee-regarding-the-outbr eak-of-novel-coronavirus-(2019-ncov).

2. Johns Hopkins University \& Medicine. Coronavirus Resource Center. https://coronavirus.jhu.edu/. 31 July 2020.

3. Therapeutic Goods Administration. Australia's first COVID treatment approved. 10 July 2020. https://www.tga.gov.au/media-relea se/australias-first-covid-treatment-approved.

4. US Food and Drug Administration. Coronavirus (COVID-19) Update: FDA Issues Emergency Use Authorization for Potential COVID-19 Treatment. 1 May 2020. https://www.fda.gov/newsevents/press-announcements/coronavirus-covid-19-update-fdaissues-emergency-use-authorization-potential-covid-19-treatment.

5. US Food and Drug Administration. Warning Letters. 1 August 2020. https://www.fda.gov/inspections-compliance-enforcemen $\mathrm{t}$-and-criminal-investigations/compliance-actions-and-activities/ warning-letters.

6. Ashley DD, Quaresima RA. Warning Letter: Seanjari Preeti Womb Healing, L.L.C. 8 May 2020. https://www.fda.gov/inspe ctions-compliance-enforcement-and-criminal-investigations/warni ng-letters/seanjari-preeti-womb-healing-llc-607355-05082020.

7. Ashely DD, Viswanathan S. Warning Letter: Butterfly Expressions LLC. 6 July 2020. https://www.fda.gov/inspections-compl iance-enforcement-and-criminal-investigations/warning-letters/ butterfly-expressions-1lc-608567-07062020.

8. US Food and Drug Administration. Coronavirus (COVID-19) Update: FDA Continues to Combat Fraudulent COVID-19 Medical Products. 7 May 2020. https://www.fda.gov/news-events/press -announcements/coronavirus-covid-19-update-fda-continuescombat-fraudulent-covid-19-medical-products.

9. National Library of Medicine. MeSH (Medical Subject Headings) Term, "Quackery". https://www.ncbi.nlm.nih.gov/ $\mathrm{mesh} /$ ?term $=$ quackery.

10. Almuryshid A, Park S, Oh SH. Effective laser treatment options for argyria: review of literatures. J Cosmet Dermatol. 2020;19:1877-82.

11. 64 Federal Register 44653, Final Rule: Over-the-Counter Drug Products Containing Colloidal Silver Ingredients or Silver Salts. 17 August 1999. https://www.gpo.gov/fdsys/pkg/FR-1999-08-17/ pdf/99-21253.pdf.
12. Papin JF, Floyd RA, Dittmer DP. Methylene blue photoinactivation abolishes West Nile virus infectivity in vivo. Antiviral Res. 2005;68:84-7.

13. Gilbert B, Akamune IE. A case of serotonin syndrome caused by the concomitant utilization of methylene blue and venlafaxine in an oncological patient. J Pharm Pract. 2019. https://doi. org/10.1177/0897190019850706.

14. Freckelton I. COVID-19: fear, quackery, false representations and the law. Int J Law Psychiatry. 2020. https://doi.org/10.1016/j. ijlp.2020.101611.

15. Stenzel TT. Warning Letter: Sonrisa Family Dental dba www. mycovidtest19.com. 15 June 2020. https://www.fda.gov/inspe ctions-compliance-enforcement-and-criminal-investigations/ warning-letters/sonrisa-family-dental-dba-wwwmycovidtest 1 9com-607748-06152020.

16. Correll WA, Quaresima RA. Warning letter: Dr. Sherrill Sellman. 1 June 2020. https://www.fda.gov/inspections-compliance-enfor cement-and-criminal-investigations/warning-letters/dr-sherrillsellman-607964-06012020.

17. Correll WA, Quaresima RA. Warning Letter: The Jim Bakker Show. 6 March 2020. https://www.fda.gov/inspections-compl iance-enforcement-and-criminal-investigations/warning-letters/ jim-bakker-show-604820-03062020.

18. The Economist. Some African politicians risk spreading covid through quackery. 30 April 2020. https://www.economist.com/ middle-east-and-africa/2020/04/30/some-african-politicians-riskspreading-covid-through-quackery.

19. Lee B-J, Lee JA, Kim K, Choi J-Y, Jung H-J. A consensus guideline of herbal medicine for coronavirus disease 2019. Integr Med Res. 2020;9:100470.

20. Jiang R, Wang K, Mao W, Zhu W, Hu W, Huang L. Chinese herbal experience for the 2019 novel coronavirus. Crit Care. 2020;24:451.

21. Bramstedt KA. The carnage of substandard research during the COVID-19 pandemic: A call for quality. J Med Ethics. 2020. https ://doi.org/10.1136/medethics-2020-106494.

22. McGuffin M, Melville S, Mister S, Israelsen L. Industry Coalition Reminds Consumers, Retailers that Dietary Supplements May Not Claim to Cure, Prevent Coronavirus. 11 February 2020. https:// www.ahpa.org/News/LatestNews/TabId/96/ArtMID/1179/Artic leID/1290/Industry-Coalition-Reminds-Consumers-Retailers-thatDietary-Supplements-May-Not-Claim-to-Cure-Prevent-Coron avirus.aspx.

23. US Food and Drug Administration. Coronavirus Treatment Acceleration Program (CTAP). https://www.fda.gov/drugs/coron avirus-covid-19-drugs/coronavirus-treatment-acceleration-progr am-ctap.

24. National Institutes of Health. NIH to launch public-private partnership to speed COVID-19 vaccine and treatment options. 17 April 2020. https://www.nih.gov/news-events/news-releases/nihlaunch-public-private-partnership-speed-covid-19-vaccine-treat ment-options

25. Correll WA, Stenzel T, Viswanathan S. Warning Letter: $21 \mathrm{st}$ Century LaserMed Pain Institute $\mathrm{d} / \mathrm{b} / \mathrm{a}$ Create Wellness Clinics. 21 July 2020. https://www.fda.gov/inspections-compliance-enfor cement-and-criminal-investigations/warning-letters/21st-centu ry-lasermed-pain-institute-dba-create-wellness-clinics-60765 4-07212020.

26. World Health Organization. Immunizing the public against misinformation. 25 August 2020. https://www.who.int/news-room/featu re-stories/detail/immunizing-the-public-against-misinformation. 